\title{
Spatiotemporal analysis of vegetation cover changes around surface water based on NDVI: a case study in Korama basin, Southern Zinder, Niger
}

\author{
Mohamed Adou Sidi Almouctar ${ }^{1}$ (1) - Yiping Wu ${ }^{1} \cdot$ Amit Kumar $^{2} \cdot$ Fubo Zhao ${ }^{1} \cdot$ Koroma John Mambu $^{3}$. \\ Mohammed Sadek ${ }^{1}$
}

Received: 22 June 2020 / Accepted: 20 November 2020 / Published online: 7 December 2020

(c) The Author(s) 2020

\begin{abstract}
In the modern era, vegetation dynamics is an important aspect of climate change studies. The present study examined spatiotemporal changes of (NDVI) normalized difference vegetation index in the Korama basin (Southern Zinder of Niger) from 2000 to 2018, and their correlation with climatic factors was predicted. To analyze the change of vegetation cover, geographical information system, MODIS_NDVI, remote sensing, and climate variables (e.g., temperature and precipitation) datasets were used. Further, the correlation was performed for different years of vegetation types during the growing season (June-October). Our results show an increasing trend in average maximum annual NDVI across the Korama River Basin in the years 2000 and 2018. Conversely, significantly increasing trends in most of the areas were reported. Moreover, in downstream the vegetation cover is increased in Matameye and Magaria, but with a smaller increase in the upstream rate in Mirriah. Furthermore, a decrease in the surface water was observed in the Tessaoua, Matameye, and Magaria sections of the study region in 2000 and 2018, while a rise in water surface area was observed in Matameye and Magaria in the years 2006 and 2012. During rainy and dry seasons, NDVI correlated differently with temperature and precipitation with strong seasonal variations, while the mean vegetation period of NDVI does not show any significant change. In addition, moderate increase was observed in years 2000 and $2012\left(r: 0.22 ; P: 0.50 ; R^{2}: 0.05 ; r: 0.31 ; P: 0.34, R^{2}: 0.10\right.$, respectively), and weak decrease in 2006 and $2018\left(r: 0.61 ; P: 0.04 ; R^{2}: 0.37 ; r: 0.58 ; P: 0.06, R^{2}: 0.33\right.$, respectively). The analysis indicates that climatic parameters such as precipitation and temperature are the main limiting factors affecting the vegetation growth. Indeed, the trends calculated by the correlation analysis showed that as climate factors increased (July, August, and September), the NDVI value increased at a rate of 0.16 , reflecting the best growth in vegetation and rise in water bodies, although significantly decreased during years. This study would be highly useful in choice-making for sustainable water resource management in the Korama watershed in Southern Zinder, Niger.
\end{abstract}

Keywords GIS · NDVI $\cdot$ Remote sensing $\cdot$ Spatiotemporal changes $\cdot$ Surface water $\cdot$ Zinder

\section{Abbreviations}

NDVI Normalized difference vegetation index

GIS Geographic information system
DEM Digital elevation model

FVC Fractional vegetation cover

CRU Climatic research unit
Mohamed Adou Sidi Almouctar sidialmoctarp@gmail.com

Yiping $\mathrm{Wu}$ yipingwu@xjtu.edu.cn

Amit Kumar amitkdah@nuist.edu.cn

Fubo Zhao zfubo789@163.com

Koroma John Mambu johnkoroma2013@gmail.com
Mohammed Sadek msadek56@yahoo.com

1 Departement of Earth and Environmental Science, School of Human Settlements and Civil Engineering, Xi'an Jiaotong University, Xi' an 710049, Shaanxi province, China

2 School of Hydrology and Water Resources, Nanjing University of Information Science and Technology, Nanjing 210044, China

3 School of Energy and Power Engineering, Xi' an Jiaotong University, Xi' an 710049, Shaanxi Province, China 


\section{EOS Earth observation system}

NASA National Aeronautics and Space Administration

SAR Sodium absorption ratio

RSC Residual sodium carbonate

\section{Introduction}

Vegetation is the key component of the earth's terrestrial ecosystems and plays a major role in soil, energy exchange, and biogeochemical cycles on earth's surface (Liu et al. 2018; Ning et al. 2015). Vegetation plays an irreplaceable function in preserving climate stability, controlling the carbon balance, and rising global greenhouse gases (GHGs), connecting soil, atmosphere, and moisture (Chuai et al. 2013; Kumar et al. 2017; 2018; Kumar and Kumar 2020). However, vegetation is prone to climate change. The dynamics of vegetation and their responses to climate change is recognized as one of the main issues of environmental change in the terrestrial ecosystem. With progress in remote sensing technologies, more information can be obtained from multispectral and multi-dated remote sensing datasets that provide advanced methods for investigating vegetation growth and inter-annual and seasonal variations (Ding et al. 2007).

The spatiotemporal variability of vegetation coverage is of great importance in the future exploring the internal relationship between vegetation and climate change, exposing the process of evolution of regional environmental conditions and forecasting future trends in growth (Zhang et al. 2018; Chauhan et al. 2020). Vegetation is the natural connection of the earth to the soil, atmosphere, and humidity. It also indicates clear signs of seasonality and inter-annual change (Chuai et al. 2013; Cui and Shi 2010) and is a touchy indicator of worldwide climate change (Weiss et al. 2004); vegetation responds simply and subtly to weather change. Nowadays, diminished soil conditions in the area affect particularly vegetation growth, in which the water system, as well as vegetation, remains vulnerable (Froend and Sommer 2010). Water resources respond to the climatological situation relatively to groundwater, providing significant protection toward climatic variability, particularly depression (Calow et al. 2010). Rouse and RH (1974) proposed the standardized difference vegetation index (SDVI), based on variations in pigment absorption characteristics in the electromagnetic spectrum's red and near-infrared regions. The complexities of vegetation have enhanced our view for vegetation seasonal growing through remotely sensed data (Meng et al. 2019). Thus, an ideal indicator of vegetation growing has called (NDVI) the normalized vegetation difference index (Piao et al. 2015). NDVI values range from -0.1 to 1.0 , that positive NDVI values suggest growing quantities of green vegetation. NDVI values close to zero and decreasing negative values suggest unvegetated characteristics such as rock and soil surfaces and water, air, ice, and clouds (Chuai et al. 2013; Schnur et al. 2010). Vegetation canopy analyzed with NDVI and remotely sensed data expose efficiently vegetation in the NIR (near-infrared) wavelengths with higher chlorophyll in the RED (red) wavelengths (Zhi-qiang and Dennis 2001). The vegetation index can largely reflect vegetation dynamics. For more details, the mathematical representation of NDVI is given as follows: NDVI $=($ NIR-Red $) /($ NIR + Red $)$, where NIR represented reflectance radiated in near-infrared wavebands and Red in the visible reflectance wavebands from the satellite. Further, it is the primary indicator of the growth and spatial pattern of vegetation (Liu et al. 1999; Purevdorj et al. 1998), as well as plant morphology (Defries and Townshend 1994; Derrien et al. 1992). Besides, weather variables (e.g., temperature and precipitation) influence vegetation growing mechanisms (Li and Tao 2000; Li 1998; Nicholson et al. 1990; Schmidt and Gitelson 2000; Zhang et al. 2003). Land-use changes and climate factors can have several effects on vegetation, including temperature and precipitation are the main indicators used to characterize climate conditions and can have a clear impact on vegetation growth (Chuai et al. 2013). Several scientists have long used the NDVI, temperature, precipitation, and other data to study the effect of climate change on vegetation. Over the last three decades, NDVI has been widely used for analyzing climatic effects on modifications on productivity of in plant life (Chuai et al. 2013; Hu et al. 2011; Nemani 2003), whereas some recent studies examined hydrological responses to vegetation cover changes. Jiao et al. (2017) analyzed the effect of vegetation dynamics on hydrological processes in a semiarid basin using a land surface hydrology coupled model and found that vegetation dynamics induced higher ET, lower runoff, and soil moisture content and decelerated the evolving trend of discharge (Zhang et al. 2019; Wu et al. (2020).

The relationship between NDVI, precipitation, and global surface temperature was studied by Schultz and Halpert (1995), and no substantial connection was found between them. Ni et al. (2006) studied the variability of vegetation and geographic characteristic. Other research observed a great relationship between these variables and recorded changes in NDVI such as (Guo et al. 2008), which were significantly associated with both temperature and precipitation. However, some of them found a positive correlation between NDVI and precipitation and reported a strong positive correlation between NDVI and temperature at high latitude (Ichii et al. 2002). Rasmussen (1998) reported that water scarcity is the key to terrestrial ecosystem efficiency and sustainability, and changes in hydrology could have large effects on the characteristics of vegetation as well as soil. Enhanced human supply for water sources (Vorosmarty et al. 2005) may have significantly changed water supply as just a global, such as the impact of climatic change (Bartram 
and Cairncross 2010). The rising of $\mathrm{CO}_{2}$ and climate variation was projected to dramatically change the global hydrological condition and has a range of effects on water source systems (Wu et al. 2012; Kumar et al. 2019). Further, the hydrological systems remain influenced by vegetation mechanisms like canopy acquisition, including water absorption from the plant (Zhao et al. 2018a). Therefore, it should be noted that the availability of water leads to good vegetation dependency, which functions are the main key by water availability (Zhao et al. 2018b).

Literature reveals that few studies have been made on water supplies and the conservation of surface water, therefore excluded from freshwater supply assessments (Calow et al. 2010). Furthermore, vegetation is the natural relation of soil, atmosphere, and humidity on Earth. It shows strong seasonal and annual shifts (Chuai et al. 2013; Cui and Shi 2010) and serves as a responsive predictor of global climate change. The change in vegetation and surface water is widely symbolic of global analysis variation in the study area where hydrological processes could better know the natural impacts and manmade disruptions on meteorological characteristics as well as predicted trends in water management (Zhao et al. 2018b). Using MODIS_NDVI satellite data, a vegetation map of Korama basin, temperature, and precipitation data, this study analyzed changes in NDVI, temperature, and precipitation and investigated the correlation between
NDVI, temperature, and precipitation for different types of vegetation across 19-year wet and dry growing seasons in Korama watershed. The objectives of this study were framed to understand the spatial change of vegetation around surface water in a changing environment in the Korama watershed and to compare the correlation between NDVI, temperature, and precipitation for different vegetation types and then to clarify the reasons for the various formed relationships. Furthermore, differences between climatic variables and MODIS_NDVI satellite data throughout 2000-2018 have also been made.

\section{Materials and methods}

\section{Study area}

The study area or basin of the Korama having a catchment area of $120,000 \mathrm{~km}^{2}$ corresponds to the extreme west of the great basin of Lake Chad and is located on the borders of Niger and Nigeria. The basin is located from east to west and limited to north and east by outcrops of the Precambrian basement of Damagaram Mounio, to the west through sedimentary deposits of the basin of Iullemenden, and to the south by way of the border of Niger-Nigeria (Fig.1). With a

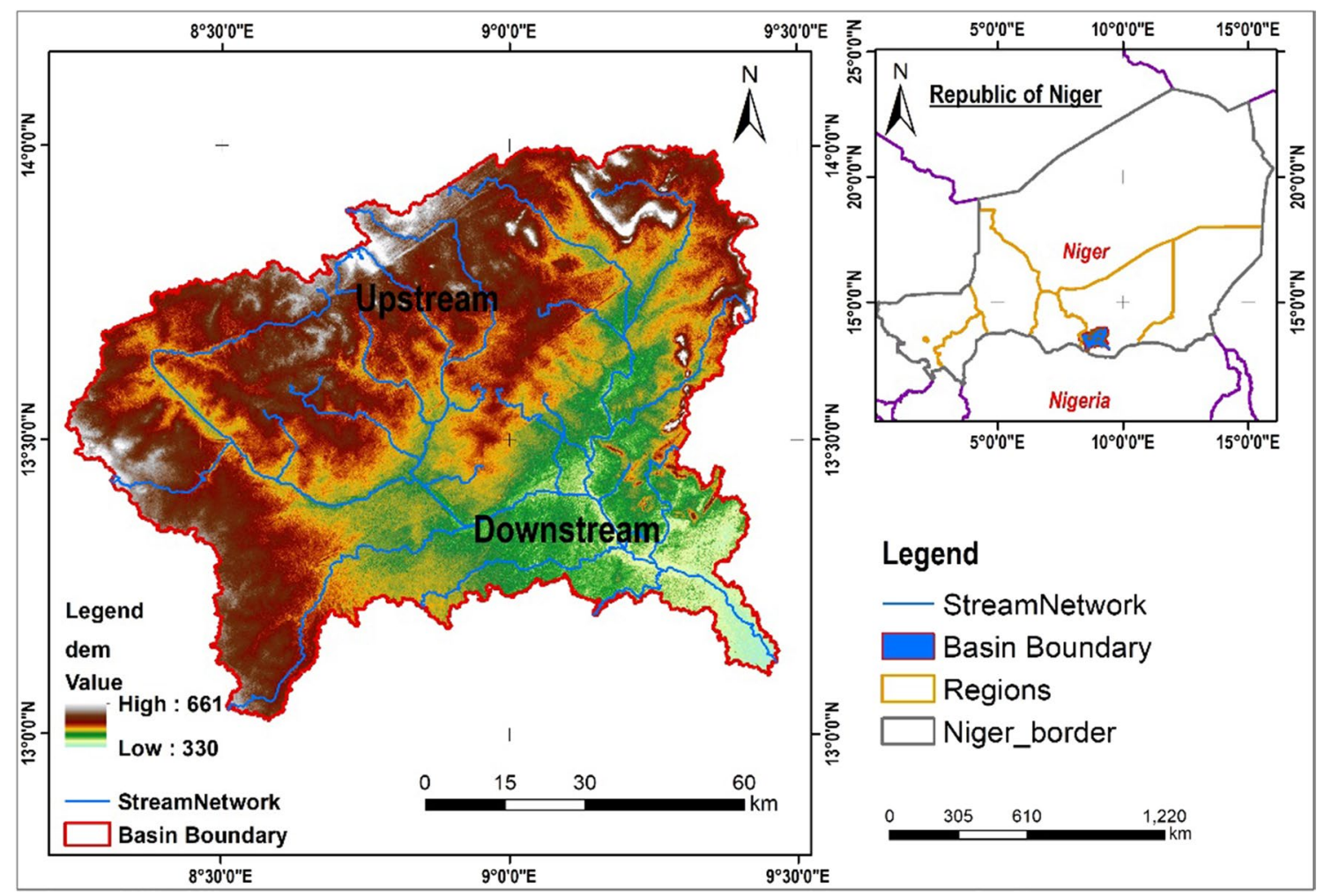

Fig. 1 Location of the study area 
density of 110 humans per $\mathrm{km}^{2}$ (Maradi 2015), the basin is one of the most populated areas in Niger.

The climate in the region is the sort of Sahel with a short rainy season (June through September) and a long dry season (October through May). The annual precipitation amounts increase $(500-600 \mathrm{~mm})$ from north to south, with an average over the period 1930-2011, from $500 \mathrm{~mm}$ to the synoptic station of Zinder airport, north of the basin, and over $600 \mathrm{~mm}$ in Magaria climate station, south of the basin. Korama River and its tributaries are part of the properly established hydrographic community within the endorheic basin. Such streams are only represented in areas, even in the rainy season, by strings of ponds (Sandao 2010). The geological map of Niger State basement complex and sedimentary basins has been in the literature (Amadi et al. 2012).

\section{Data description}

The current study used remote sensing and satellite data to analyze vegetation and water body changes based on NDVI via spatial approach over the period from 2000 to 2018. A (DEM $90 \mathrm{~m}$ of resolution) was obtained from NASA satellite, (https://earthexplorer.usgs.gov/). MODIS/TERRA MOD13Q1vegetation indices 16 days L3 Global $250 \mathrm{~m}$, with high-resolution satellite data for the years 2000, 2006, 2012, and 2018, respectively, were obtained from NASA's earth observation system (https://earthexplorer.usgs.gov/). The climate variable (e.g., temperature, precipitation) from 1900 to 2017 was obtained from CRU web satellite data, (https://www.cru.uea.ac.uk/data). These datasets have been designed for a well appreciative of our research area analysis by using datasets from the years 2000, 2006, 2012, and 2018, respectively. Hydrometeorological data collected for this study are given in Table 1.

\section{Methodology adopted}

\section{Approach for the spatial and temporal analysis of NDVI}

The method to improve the reflectance radiated in the NIR near-infrared bands and the reflectance radiated in the red visible bands was used to synthesize monthly NDVI data based on MODIS data from the preprocessed time and obtain the annual NDVI dataset. The method of trend analysis was used to analyze patterns in the annual, interannual, and spatial NDVI variability. This approach employs a minimum square method to match the NDVI variance trend slope over a certain period of time, and it can be used to completely represent the spatiotemporal characteristics of changes in vegetation. Remote sensing and the various computational software and/or statistical tools, such as Excel, word, ArcGIS, Origin Lab, were used for the satellite data from NASA Earth Observation System (EOS) for February 21, 2019, for extraction of hydrological features in the GIS system (Arc Map 10.3 software). The area of water was extracted from the attribute tables by calculating geometry from 2000 to 2018. Further, NDVI could be analyzed from imagery data and recognized as valid plants covering indicators (Olusegun and Adeyewa 2013; Hess et al. 1996). Buffer analysis within the GIS environment was accomplished to know the variability in the NDVI response and further estimate the temporal changes around the surface water. Thus, vegetation patterns were widely investigated due to variability in the water cycle and climatic parameters. The amount of NDVI from -1 and 1 , where after classifying a greater value, indicates greater vegetation, whereas low value generally means less vegetation cover (Stow al. 2003). The watershed was delineated from DEM and further created a separate basin (Fig. 2).

To be consistent in this study, MODIS/TERRA MOD13Q1 vegetation indices 16 days L3 Global $250 \mathrm{~m}$, of the year 2000, 2006, 2012, and 2018 would be utilized to analyze the correlation between climatic parameters and vegetation growing. The correlations coefficient and band

Table 1 Hydrometeorological data collected

\begin{tabular}{llll}
\hline Data collected & Format of data & Details of data & Source \\
\hline DEM & Raster & SRTM with a 90-m resolution & (https://earthexplorer.usgs.gov/ \\
$\begin{array}{l}\text { MODIS/TERRA } \\
\text { MOD13Q1 }\end{array}$ & Raster & Vegetation indices 16 days L3 Global 250 m & https://earthexplorer.usgs.gov/ \\
Precipitation & Text file & Average precipitation & www.cru.uea.ac.uk \\
Temperature & Text file & Min and max temperature & www.cru.uea.ac.uk \\
Precipitation & Raster & Zip file containing 12 Geo Tif (.tif) files , 30m resolution & https://worldclim.org/data/worldclim21.html \\
Temperature & Raster & Zip file containing 12 Geo Tif (.tif) files , 30 m resolution & https://worldclim.org/data/worldclim21.html \\
\hline
\end{tabular}




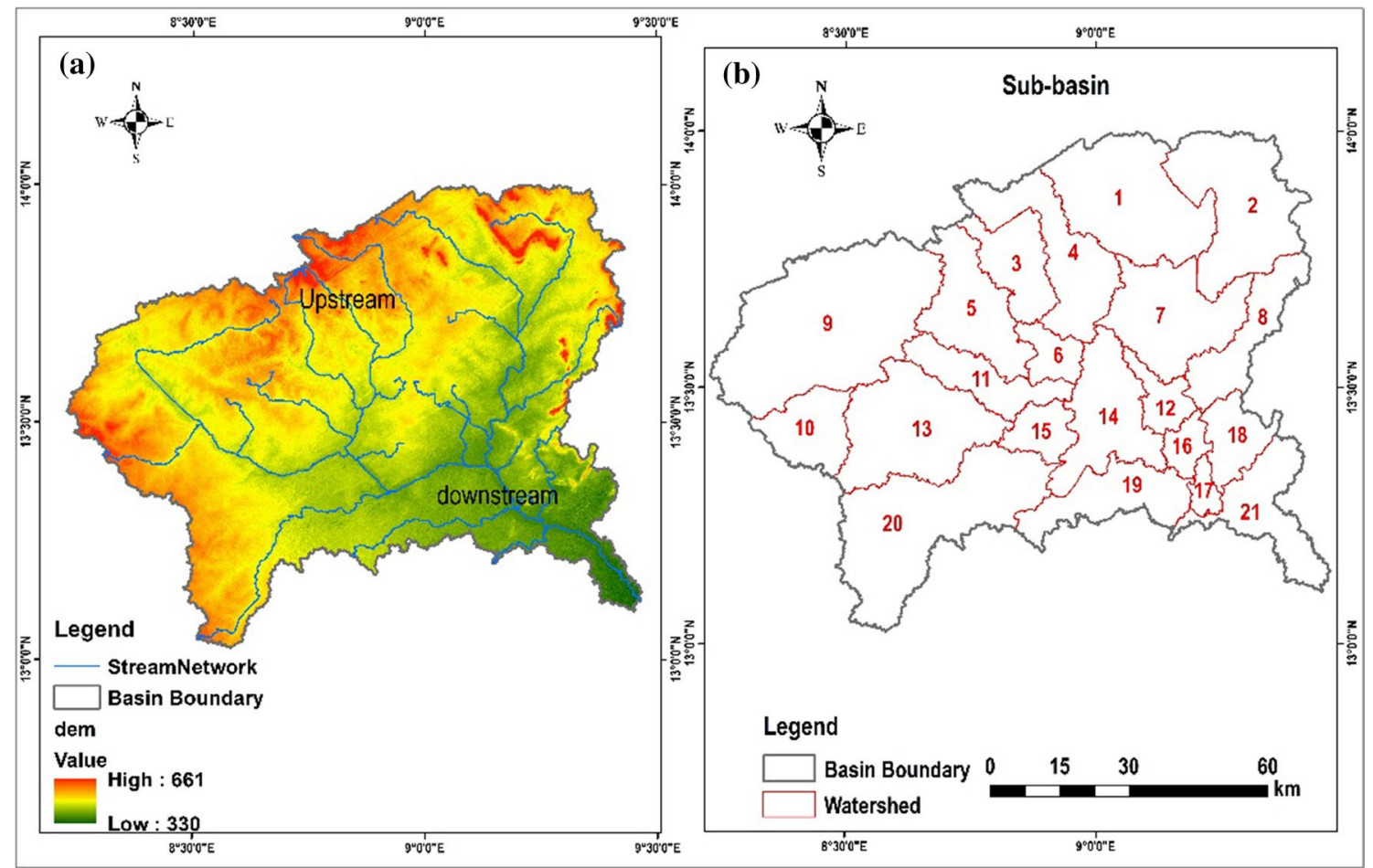

Fig. 2 a DEM of study catchment and b Sub-basin created

collection statistics were used to calculate the correlation matrix. Furthermore, to understand the relation among climatic variables and NDVI, ordinary correlation equation analyses were performed and then showed a linear correlation. The correlation coefficient is formulated as follows:

$r_{\mathrm{xy}}=\frac{\sum_{i=1}^{n}(x-\bar{x})\left(y_{i}-\bar{y}\right)}{\sqrt{\sum_{i=1}^{n}\left(x_{i}-\bar{x}\right)^{2}} \times \sqrt{\sum_{i=1}^{n}\left(y_{i}-\bar{y}\right)^{2}}}$

where $x_{i}$ represent monthly NDVI value, $\bar{x}$ mean value of NDVI in the year, $y_{i}$ monthly climatological parameter, $y$ mean value of climatological parameters in the year, $n=12, r_{x y}$ mean correlation coefficient among climatic variables and MODIS_NDVI. NDVI helps to examine growth and greenness of vegetation in a particular region. It is the ratio of the difference in reflectance near-infrared bands and reflectance in the visible bands to their sum (Rouse and RH 1974; Weiss et al. 2004; Kumar et al. 2017), and the mathematical representation is given in Eq. 2.

$\mathrm{NDVI}=\frac{\mathrm{NIR}-\mathrm{RED}}{\mathrm{NIR}+\mathrm{RED}}$

where NIR is the reflectance in the near-infrared band and RED the reflectance in the visible band. Its value ranges +1 to -1 , positive values represent healthy vegetation cover, and negative values represent poor vegetation cover (Wang et al. 2020).

Vegetation cover is calculated through the NDVI value mapped in the studied catchment. The NDVI usually varies around 0.1 and 0.7 in heavy vegetation fields, as different to green vegetation. Moreover, water has more visible reflectance, that NIR arising in a negative value of NDVI, whereas some areas such as bare soil and rock provide the equal value of NDVI in both bands and close to zero (Rouse and RH 1974). In Equation 3, the interaction among NDVI and FVC scaled was shown (Carlson and Repley 1997):

$\mathrm{FVC} \approx(\mathrm{NDVI})^{2}$

where FCV (fractional vegetation cover) represents a reasonable approximation of vegetation cover area pixel percentage and generally represents a good indicator for vegetation cover estimation. Thus, fractional vegetation cover varies from zero to one.

Generally, MODIS/TERRA MOD13Q1vegetation indices 16 days $\mathrm{L} 3$ Global $250 \mathrm{~m}$ provides an interesting view of variation across ecosystems with higher spatial frequency, thereby providing a strong benchmark for future change assessment. 


\section{Results and discussion}

\section{Estimation of change detection in NDVI (2000-2018)}

The NDVI was used to determine green vegetation production and for detecting changes in vegetation. It is also widely used to calculate the interaction among atmospheric variation and the level of vegetation growing. After classifying high and low vegetation, a pixel with high NDVI values indicates high vegetation, whereas low NDVI value generally means less vegetation (Fig. 3). Furthermore, negative NDVI values are the best factor for water bodies. Hence, the annual variation in the growing season NDVI, precipitation, and temperature for different types of vegetation is illustrated in Fig 3. The mean NDVI vegetation period has not substantially changed. But a moderate increase was observed in the years 2000 and 2012 ( $r: 0.226 ; P: 0.503 ; R^{2}: 0.051 ; r: 0.317 ; P: 0.341$, $R^{2}: 0.100$, respectively) and substantially decrease in 2006 and $2018\left(r: 0.610 ; P: 0.046 ; R^{2}: 0.372 ; r: 0.581 ; P: 0.060\right.$, $R^{2}: 0.337$, respectively). Further, Fig. 3 shows changes in the growing season (NDVI from 2000 to 2018 in Korama basin, Zinder, Niger). The investigations show that most of the water sources have reduced in their aerial extent and some of them have even disappeared. Significantly, surface water areas have been reducing from general to particular in the study area. It is due to the intensification and expansion of the agricultural area, urbanization, and agricultural land use of chemicals (pesticides), which causes additional vegetation reduction.

Figure 3 reveals that NDVI variability corresponded well with precipitation variations in wet seasonal vegetation, increasing that seasonal precipitation was relatively high in 2000 and 2012 with values $(0.723$; and 0.722 , respectively) and low in 2006 and 2018 with values (0.658; and 0.692, respectively), coinciding with peaks and troughs in rising season NDVI. The average precipitation during the growing season in 2000 and 2012 and the minimum in 2006 and 2018 , respectively, corresponded to the maximum and minimal NDVI. Additionally, band collection statistics with Pearson's correlation analysis has applied and reported mixed results among climates parameters and NDVI. Similarly, Fig. 4 shows the maps of the NDVI correlation coefficients per season and climatic variables. Many positive correlations of NDVI temperature are distributed in a wet period in the
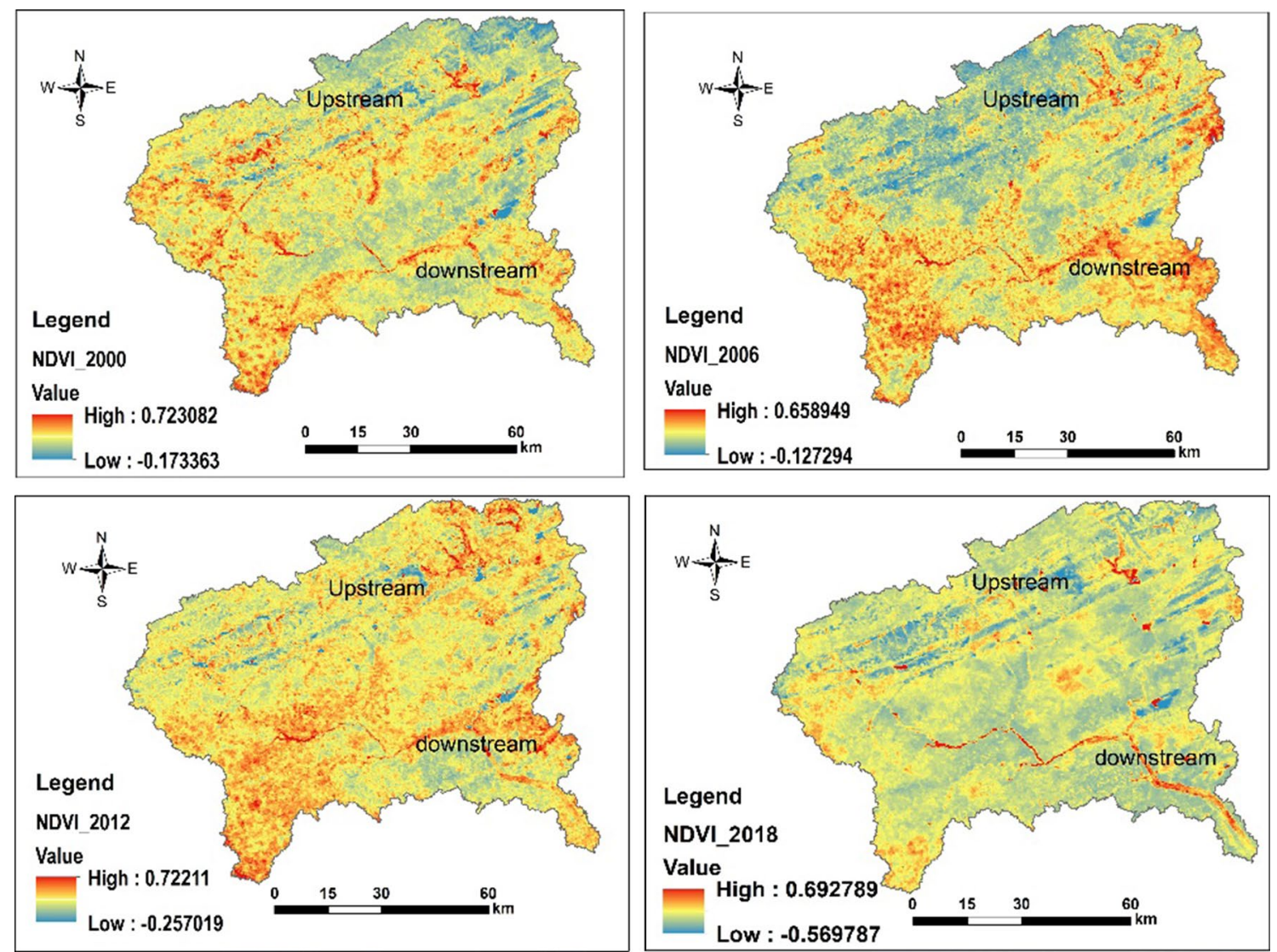

Fig. 3 The changes in growing season NDVI from 2000 to 2018 in Korama basin, Zinder, Niger 

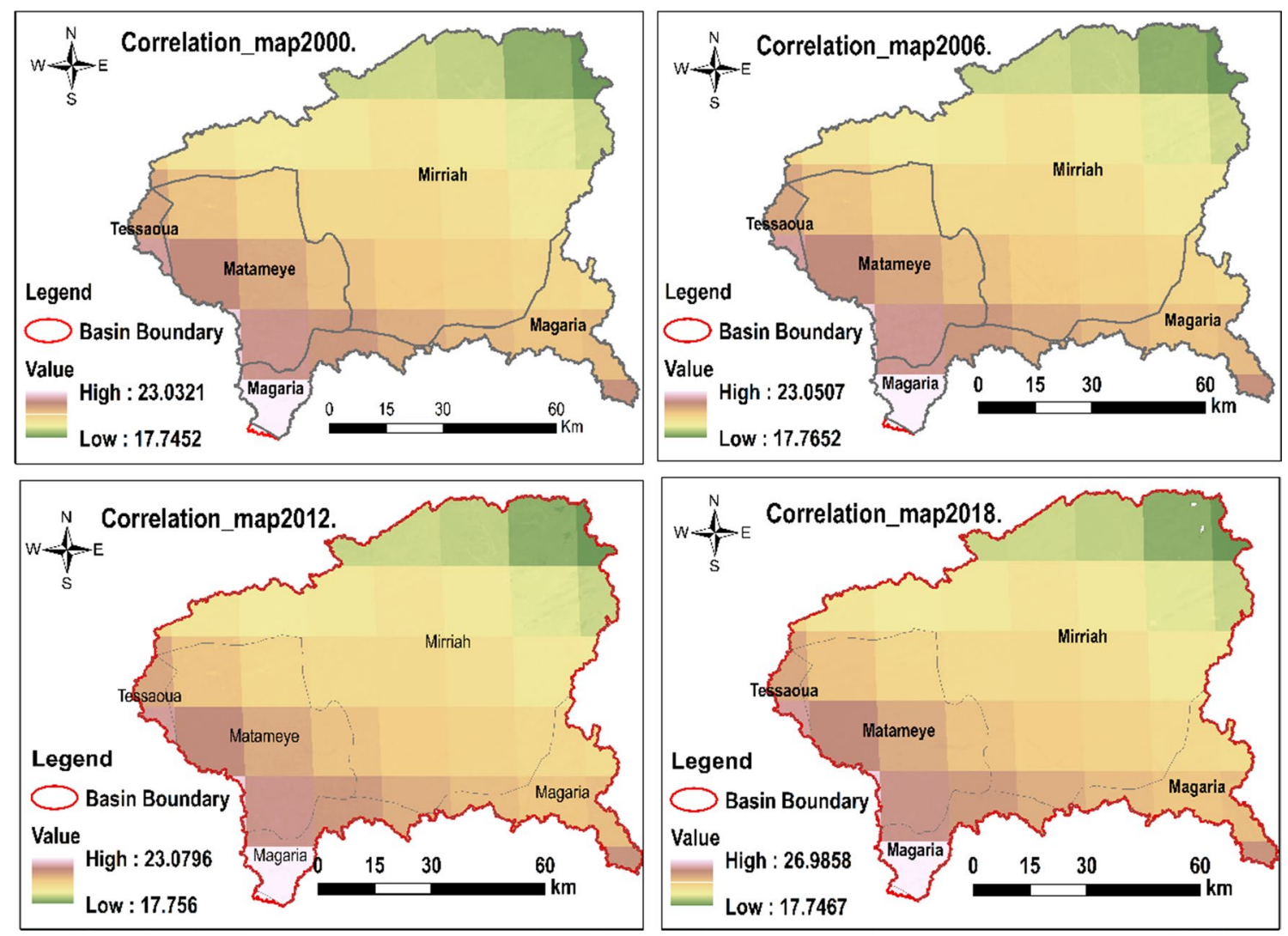

Fig. 4 Maps of the NDVI correlation coefficients per season and climatic variables

west, where the higher correlation was observed in the years 2000 and 2018 (23.0321, 230507, 230796, and 26.9858, respectively) and low correlation (17.7452, 177652, 17756, and 17.7467 , respectively). During summer, the area of positive correlation shifts from the southern areas (Matameye) to the eastern (Mirriah) as shown in Fig. 4. NDVI tends to be greatly affected by temperature in these areas at the start of the growing season. Areas of negative correlations with NDVI temperature correlated well with areas with positive NDVI-precipitation correlations, often in semiarid regions. In these regions, inter-annual variability of NDVI was determined by temperature as well as precipitation. As the correlation of NDVI-precipitation is higher than that of NDVI-temperature, precipitation is considered to have the dominant effect on the growth of vegetation in the semiarid area.

Figure 4 shows that, for all vegetation types, NDVI correlated positively with temperature in the Magaria and Tessaoua parts of the study area. NDVI is also positively correlated with precipitation for all parts of vegetation cover except for the Southern part of the study area (i.e., Mirriah). However, these results suggest that the warmer environment and increased precipitation in Korama basin are critical for most vegetation cover areas to grow in the wet season.
Furthermore, higher temperatures and low precipitation are advantageous for the growth of vegetation in the wet season, as they are situated under conditions of ample precipitation, and more precipitation will lower temperature, as described above. However, it is more complex to measure the correlation with surface water and climatic parameters variable. So in this work, from each NDVI values, the change analysis is an important way to define the variations detected from 2000 to 2018 . This research suggests how varying patterns and procedures may be detected at more than one scale the usage of alternate in NDVI values.

\section{Interannual changes of vegetation (2000-2015)}

Water deficit is positively correlated NDVI as water-deficit stress occurs, the soil becomes green (Fig. 4), and NDVI is decreasing, followed by vegetation undergoes a regression. Furthermore, interannual trends during the period of 2000-2018 were analyzed based on the climate correlation maps obtained in this study. Results show the rise in NDVI characterized by a positive NDVI temperature dependence. Thus, temperature is one of the most significant factors influencing NDVI. In the years of 2006 and 2018, the decline in precipitation is correlated with a decrease in NDVI, as 
precipitation plays a vital role in plant production in these semiarid regions. Although there was a strong coefficient of correlation between NDVI and precipitation in the area because it is known that the analysis of detection changes of vegetation cover is due to the availability of water in the soil. However, some variation of NDVI values in the most study area is widely shown during 2000-2018.

In all years from 2000 to 2018, there was a respectable vegetation cover around a water body in Tessaoua, Matameye, and Magaria parts of the study area, while a decrease in vegetation was observed in Mirriah part of the years 2000 and 2006. This might be due to a good tendency of precipitation with a decrease in temperature in the parts with good vegetation coverage and a decrease in precipitation with higher temperature during the time of vegetation decrease.

The correlation was explored between the interannual differences throughout the NDVI as well as the climate variables. It has been shown that the interannual temperature variability, especially in the increasing season, has a significant effect on ecosystem activity in the high latitude area. The growth of vegetation in semiarid regions is mainly restricted through precipitation, although water resource, as the primary cause during plant growth, is often not directly linked to the arid and semiarid areas. But for two reasons in a regular climate with abundant wet-season water followed by a noticeable dry season. First, throughout the rainy season, the groundwater is sufficiently charged (Adimalla et al. 2020). Secondly, related to higher rainfall and resource for higher production, an improved performance can restore and spread carbon through the process, enabling plants to have greater implications for deeper resource access (Liu et al 1999; Rana et al. 2020), although the good reaction of vegetation to a climatic parameter such as precipitation suggests that ecosystem growth and development are linked by precipitation.

\section{Relationship between NDVI and climatic variables}

There is a need to note a similarity in the seasonal of the NDVI index in the study area during the period 2000-2018. The correlation between annual average NDVI and climatic variables is shown in Fig. 3; the figure shows time-analyzed and distribution of the relationship between NDVI and climatic factors. A positive correlation between NDVI and temperature was found in Southern Niger during the wet period, while in the dry season negative correlations were detected. Figure 4 shows that seasonal NDVI is positively correlated with temperature in the Korama basin (Magaria and Tessaoua sections). During the wet season, the correlation was significantly positive, slowly weakening in the drying season. The correlation between NDVI and temperature during the dry season was slightly negative, especially in the summer months (Fig. 5). Similarly in the rainy season
(August-October), the correlation was greater than in the summer. In summary, areas with positive correlations across the entire Korama basin were greater than with negative correlations. On the other hand, the NDVI-precipitation correlation is distinct from the NDVI-temperature correlation (Fig. 6). In southern Korama, the positive correlation is pronounced, which is distinctly different from the rest of the cold climate zone. Besides the systematic examination of the correlation, coefficient values, we noticed that the coefficient spatial correlation between NDVI and precipitation was very different for NDVI depending on the period of the growing season, the time interval, and the period during which precipitation was accumulated, and the form of land cover. Therefore, climate change can be attributed as a cause of changes in climatic parameters, especially temperature and precipitation. These parameters are vital factors for plant growth (Wang et al. 2020).

The NDVI levels start to rise in 0.11 and hit their peak values to 0.16 and then decline thereafter, representing the best vegetation growth in the area (Fig. 6), decrease for the NDVI values indicating less vegetation growth. Furthermore, Table 2 shows the difference of correlation coefficient between the Pearson coefficient and R-square, which were calculated, however, that the slope is substantially different to 0 , while NDVI is already at 0.05 rate, which indicates the coefficient of Pearson correlation among climatic parameters and satellite data throughout the rising time of the year from 2000 to 2018 . Besides, trough analysis by using the technique of change detection based on its characteristics such as vegetation in the area, hence the detection of vegetation cover variation with MODIS_NDVI values threshold of $0.73,0.72,0.65$, and 0.69 , respectively. The most precipitation, in the three months (July, August, and September), of cumulative rainfall has decreased, while NDVI values have significantly decreased during analysis (Fig. 6). Further, the correlation between climate variability and NDVI time's variable with $500-600 \mathrm{~mm}$ of mean precipitation in the area was good as shown in Fig. 7. Overall, the relationship with a certain precipitation threshold is roughly linear, but NDVI values change moderately as do annual precipitation. So the absolute values of precipitation were greater than the temperature in the wet season, which means, during growing season, NDVI is more susceptive with precipitation. Figure 3 shows the temporal variation of the NDVI trend from 2000 to 2018.(Fig. 8)

The impacts of the climatic variable on plant growth, during 2000-2018 were analyzed. In this regard, the interaction between climate factors and NDVI was assessed. The coefficient of correlation was carried out for climate lead time for precipitation and temperature. Since a positive NDVI-climate variable correlation was observed as shown in Fig. 6, in lead time duration, the correlation was conducted throughout the climate variable and NDVI time series. Analysis results 

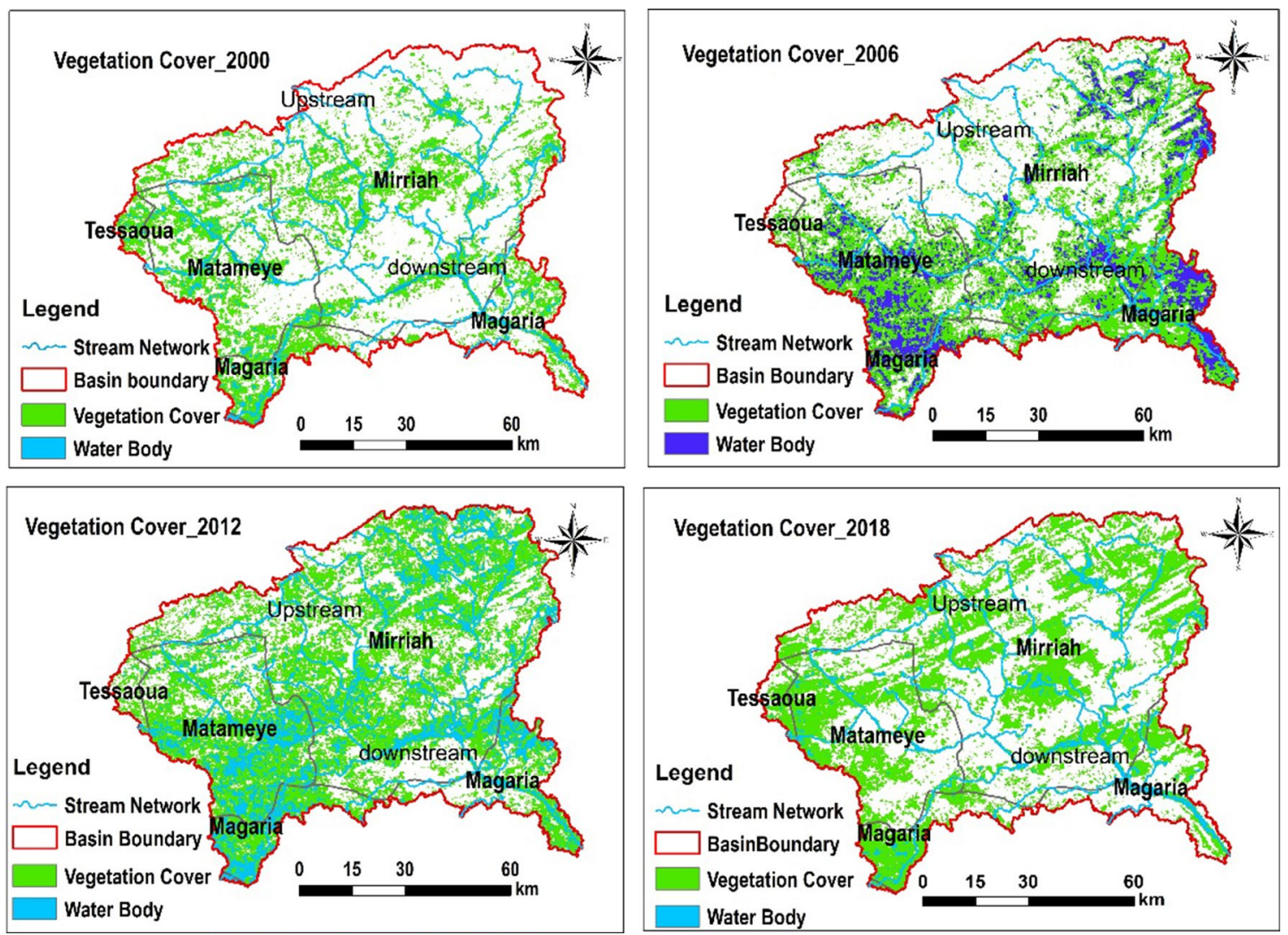

Fig. 5 Change in vegetation cover around the water body by different parts of the Korama basin. From 2000 to 2018

found that the variability in vegetation growth is linked to climate variables (e.g., precipitation and temperature) and human activities (e.g., fertilization and irrigation). However, Fig. 7 shows the change of meteoroidal graphs from 1901 to 2017 (annual temperature $\left({ }^{\circ} \mathrm{C}\right.$ ) and annual precipitation total $(\mathrm{mm})$ ), which was used to analyze the climate variability during a period $1901-2017$ by using observed and CRU data.

The interaction between NDVI and its cumulative effects on the future and/or regional climate has been analyzed by applying band collection statistics and basic statistical parameters (e.g., minimum, maximum, mean, and standard deviation) for every layer. The results of the correlation between NDVI are given in Table 3.

Table 3 shows an analysis of a set of NDVI raster calculations from 2000 to 2018 using the correlation matrix option. Further to proceed only the basic statistical measurements (mean, minimum, maximum, as well as standard deviation), we will be calculated for each layer. This is a default value, other than the standard, which calculates the dataset of NDVI raster bands from 2000 to 2018. However, the correlation matrix between each layer (NDVI) will also be determined. Furthermore, the correlation matrix results for bands collection statistics between NDVI 2000, 2006,
2012, and 2018, respectively, showed as layers: layers 1 and 2 (0.528), layers 1 and $3(0.507)$, layers 1 and $4(0.047)$, layers 2 and $3(0.543)$, layers 2 and 4 (0.306), and layers 3 and 4 (0.421), respectively. NDVI option allows greater results for vegetation that vary in density and also for vegetation dispersed from spatial images of different time series, whereas the study suggests that variability of vegetation growth pattern is linked to climate variable (e.g., precipitation and temperature).

\section{Impact on vegetation growth of surface water quality parameters in Korama Basin}

Since 1990 s, vegetation variability response to water soil has been an actively studied area of research at a regional and/or global scale in the context of changing climate and anthropogenic activities. The area under study climate conditions and topography is mainly affected by the dynamic changes in the vegetation cover. Moreover, climate change directly affects the growth of vegetation, while landscape conditions influence the distribution of water and heat at the surface. Vegetation and ecosystem services regulation in the watershed development and evolution is linked to the hydrological situation system

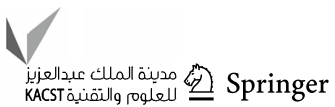



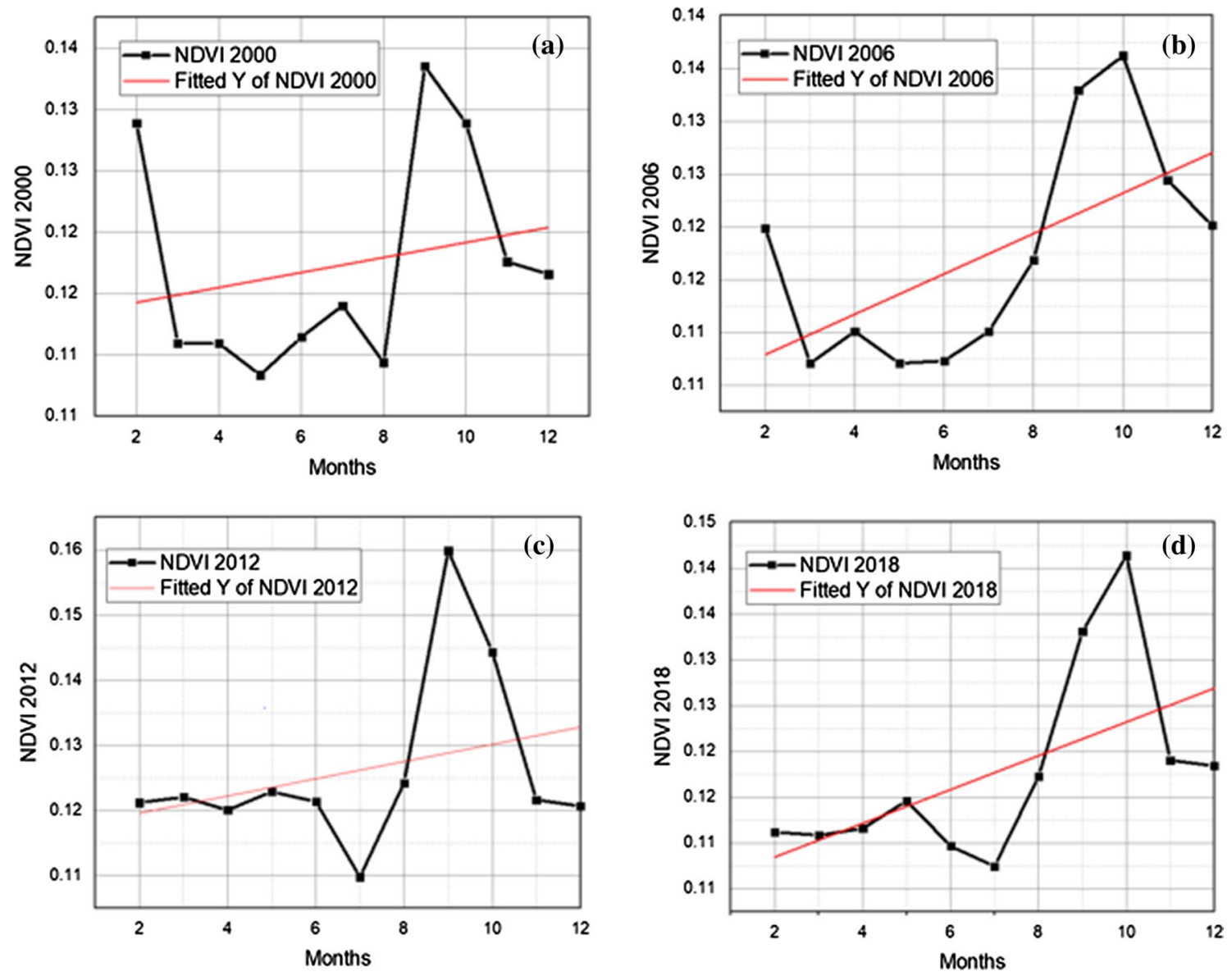

Fig. 6 Temporal variation of NDVI trend from 2000 to 2018. a NDVI trend from 2000 b NDVI trend from 2006 c NDVI trend from 2012 , d NDVI trend from 2018 in Niger

(Zipper et al. 2018). Sandao et al. (2010) conducted the study to see the impact of surface water quality parameters on vegetation growth based on physicochemical data (conductivity, salinity, residual sodium (SAR) and residual carbonates) and stated that water is poorly mineralized in the area and suitable for irrigation. Besides, they calculated the sodium absorption ratio (SAR) and completed a Table of Classification of water for irrigation, according to the SAR values and conductivity. Furthermore, they applied the method of residual sodium carbonate (RSC) and categorized the suitability of water for irrigation into three classes: (i) RSC below or equal to 1.25 indicates a

Table 2 Difference between Pearson coefficient and R-Square

\begin{tabular}{lllll}
\hline & NDVI_2000 & NDVI_2006 & NDVI_2012 & NDVI_2018 \\
\hline $\mathrm{y}=\mathrm{a}+\mathrm{b}^{*} \mathrm{x}$ & & & & \\
Pearson's $\mathrm{r}$ & 0.22 & 0.61 & 0.31 & 0.58 \\
R-Square & 0.05 & 0.37 & 0.10 & 0.33 \\
$P$ value & 0.50 & 0.04 & 0.34 & 0.06 \\
\hline
\end{tabular}

good quality water for irrigation; (ii) RSC between 1.25 and 2.5 indicates average quality water for irrigation, and (iii) RSC above or equal to 2.5 indicates salty water and unsuitable for irrigation. The values of groundwater physical parameters, measured in situ (conductivity, $\mathrm{pH}$ and temperature), show that the values of groundwater conductivity in the Korama basin vary from 51 to $825 \mu$ s/ $\mathrm{cm}$, with an average of $221 \mu \mathrm{s} / \mathrm{cm}$. These values show that more than $95 \%$ of the water has conductivity below or equal to $750 \mu \mathrm{s} / \mathrm{cm}$. This quality of water is coming within the good and excellent classes for irrigation. Groundwater in the area is generally acidic or rarely neutral ( $\mathrm{pH}$ below or equal to $7 \mathrm{pH}$ units). This parameter has not been specifically studied by the use of such water for irrigation. Further, the values of groundwater temperature, between $20{ }^{\circ} \mathrm{C}$ and $27{ }^{\circ} \mathrm{C}$, are close to annual average values of the atmospheric temperature in the area. These temperatures do not seem to have side effects on the suitability of water for irrigation. In addition to water quality, climate variables and anthropogenic disturbance, NDVI may also be affected by soil degradation, air pollution, slope, and 
Fig. 7 Comparative study of NDVI values of the time series from 2000, 2006, 2012 and 2018

Fig. 8 a Annual temperature $\left({ }^{\circ} \mathrm{C}\right)$ and $\mathbf{b}$ Annual precipitation total (mm) of Zinder from 1901 to 2017
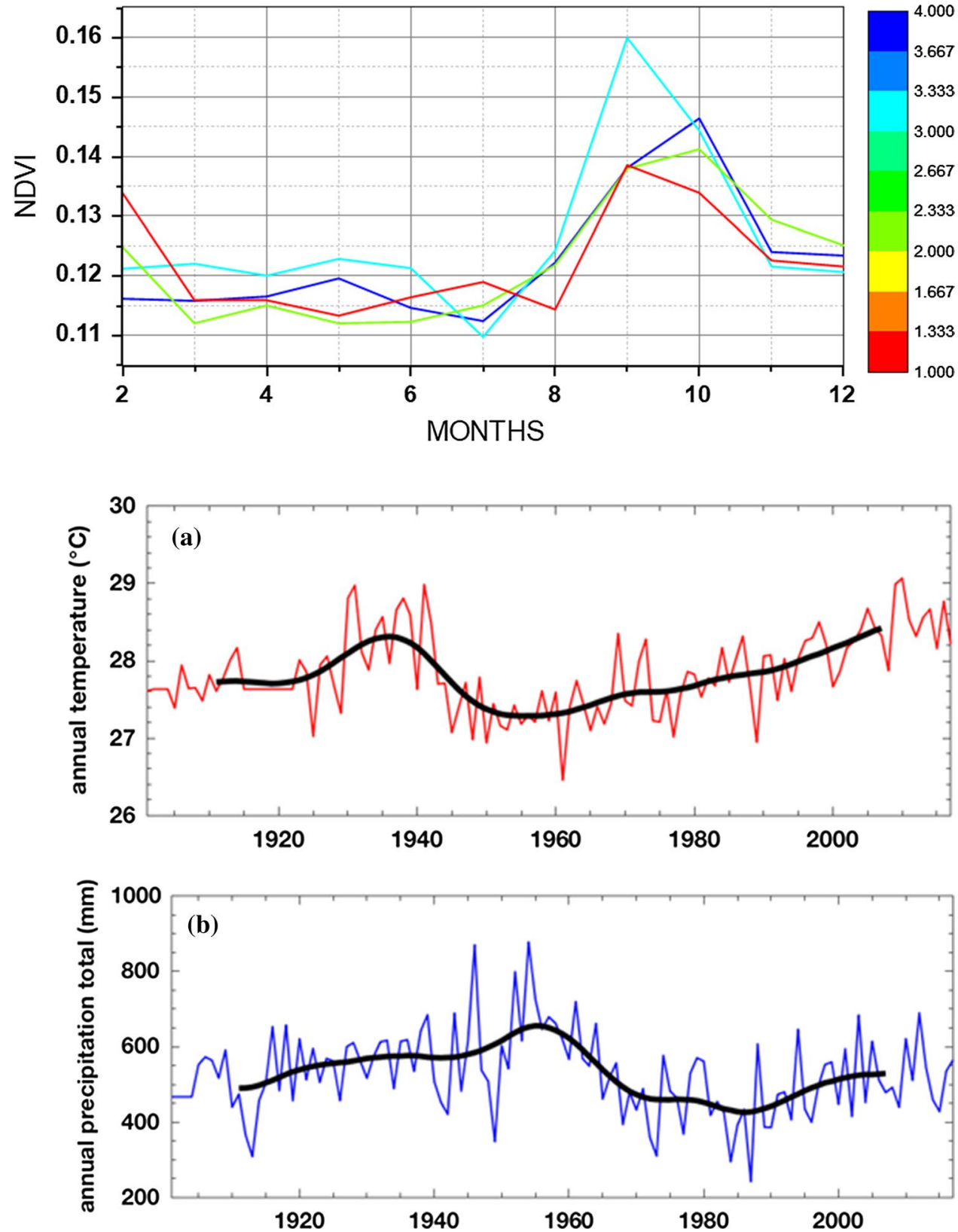

\begin{tabular}{lllll}
\hline Layer & NDVI_2000 & NDVI_2006 & NDVI_2012 & NDVI_2018 \\
\hline NDVI_2000 & 1.00 & 0.52 & 0.50 & 0.47 \\
NDVI_2006 & 0.52 & 1.00 & 0.54 & 0.30 \\
NDVI_2012 & 0.50 & 0.54 & 1.00 & 0.42 \\
NDVI_2018 & 0.47 & 0.30 & 0.42 & 1.00 \\
\hline
\end{tabular}

Table 3 Analysis of a set of NDVI raster calculations from 2000 to 2018 using the correlation matrix option researchers working on climate change, globally. Therefore, good data image resolution and time-series datasets other miscellaneous factors. But the impact of these fac-
tors on vegetation change has become a difficult task to the 
and key factors affecting NDVI will be the main direction of our upcoming research.

\section{Conclusion}

In this study, the trend analysis method was used, based on temporal MODIS_NDVI data, to analyze the spatiotemporal variability in the vegetation cover throughout the Korama basin from 2000 to 2018. Based on meteorological and topographical evidence, the principal factors influencing the vegetation cover variations were investigated. Results reveal that the overall growth rate of NDVI in the study area across 19 years has been 0.16 in the downstream areas of the basin, while vegetation cover is found larger compared to the upstream areas. Similarly in the upstream areas, NDVI changes are small, with little fluctuation, whereas downstream changes are larger. The areas with increasing trends are distributed primarily in the downstream region, while the areas with declining trends are concentrated in the upstream portion of the basin. Areas with substantial increases in the spatial distribution of vegetation cover are primarily located near the section of Magaria, and major decreases in cover distribution are found near the central section and Mirriah.

The NDVI shows a significant positive correlation with a climatic variable in the area under study. The associations between the NDVI and temperature and precipitation are variable in different regions. The precipitation in the upstream of the river greatly affects the forest areas, but meanwhile, the temperature in the upper basin reaches greatly affects the lower region. All the climate factors have little influence on the plain's agricultural areas, while they have a greater combined impact on the basin's central region with smaller individual impacts. Therefore, this study helps to understand the relationship between the NDVI, environment, and human factors and may offer suggestions for sustainable management in the Korama watershed. Further, the results of this study provide a reference for sustainable environmental management and response to vegetation change in the context of climate change.

Acknowledgements This work was performed under the supervision of Dr. Yiping Wu. Xi' an Jiaotong University, Institute of Global Environmental Change, in Earth and Environmental Science department. We are also grateful to the Chinese Scholarship Council for financial support.

Author contributions All authors contributed to research design, data interpretation, and literature search and in writing manuscript. All authors read and approved the final manuscript. The authors are highly thankful to the reviewers and editors for fruitful comments to improve the quality of the paper.

Funding Yiping Wu work was funded by the Ministry of Science and Technology of the People's Republic of China (2013FY112500). The funders had no role in study design, data collection and analysis, decision to publish, or preparation of the manuscript.

Data availability The data supporting our analyses can be accessed publicly from the link provided in the paper, and we will also share the data soon after the manuscript is published.

\section{Compliance with ethical standards}

Conflict of interest The authors declare that they have no competing interests.

Open Access This article is licensed under a Creative Commons Attribution 4.0 International License, which permits use, sharing, adaptation, distribution and reproduction in any medium or format, as long as you give appropriate credit to the original author(s) and the source, provide a link to the Creative Commons licence, and indicate if changes were made. The images or other third party material in this article are included in the article's Creative Commons licence, unless indicated otherwise in a credit line to the material. If material is not included in the article's Creative Commons licence and your intended use is not permitted by statutory regulation or exceeds the permitted use, you will need to obtain permission directly from the copyright holder. To view a copy of this licence, visit http://creativecommons.org/licenses/by/4.0/.

\section{References}

Adimalla N (2020) Assessment and mechanism of fluoride enrichment in groundwater from the hard rock terrain: a multivariate statistical approach. Geochem Int 58(4):456-471

Amadi AN, Olasehinde PI, Okoye NO, Momoh OI, Dan-Hassan MA (2012) Hydrogeophysical exploration for groundwater potential in kataeregi, Northern-Central Nigeria. Int J Sci Res 2:9-17

Bartram J, Cairncross S (2010) Hygiene, sanitation, and water: forgotten foundations of health. PLoS Med 7(11):e1000367. https://doi. org/10.1371/journal.pmed.1000367

Calow RC, MacDonald AM, Nicol AL, Robins NS (2010) Groundwater security and drought in Africa: linking availability, access, and demand. Groundwater 48(2):246-256

Carlson TN, Repley DA (1997) On the relation between NDVI, fractional vegetation cover, and leaf area index. Remote Sens Environ 62(3):214-252. https://doi.org/10.1016/S0034-4257(97)00104-1

Chauhan M, Kumar M, Kumar A (2020) Impact of carbon stocks of Anogeissus latifolia on climate change and socio-economic development: A case study of Garhwal Himalaya India. Water Air Soil Pollut 231(8):1-15. https://doi.org/10.1007/s11270-020-04803-8

Chuai XW, Huang XJ, Wang WJ, Bao G (2013) NDVI, temperature and precipitation changes and their relationships with different vegetation types during 1998-2007 in Inner Mongolia, China: changes in NDVI, temperature and precipitation in inner Mongolia. Int J Climatol 33(7):1696-1706. https://doi.org/10.1002/joc.3543

Cui L, Shi J (2010) Temporal and spatial response of vegetation NDVI to temperature and precipitation in eastern China. J Geogr Sci 20(2):163-176. https://doi.org/10.1007/s11442-010-0163-4

DeFries RS, Townshend JRG (1994) NDVI-derived land cover classifications at a global scale. Int J Remote Sens 15(17):3567-3586

Derrien M, Farki B, Legleau H, Sairouni A (1992) Vegetation cover mapping over France using NOAA-11/AVHRR. Int J Remote Sens 13(9):1787-1795

Ding M, Zhang Y, Liu L, Zhang W, Wang Z, Bai W (2007) The relationship between NDVI and precipitation on the Tibetan Plateau. J Geogr Sci 17(3):259-268 
Froend R, Sommer B (2010) Phreatophytic vegetation response to climatic and abstraction-induced groundwater drawdown: examples of long-term spatial and temporal variability in community response. Ecol Eng 36(9):1191-1200

Guo N, Zhu YJ, Wang JM, Deng CP (2008) The relationship between NDVI and climate elements for 22 years in different vegetation areas of northwest China. J Plant Ecol 32(2):319-327

Hess T, Stephens W, Thomas G (1996) Modelling NDVI from decadal rainfall data in the North East Arid Zone of Nigeria. J Environ Manag 48(3):249-261

Hu MQ, Mao F, Sun H, Hou YY (2011) Study of normalized difference vegetation index variation and its correlation with climate factors in the three-river-source region. Int J Appl Earth Obs Geoinf 13(1):24-33

Ichii K, Kawabata A, Yamaguchi Y (2002) Global correlation analysis for NDVI and climatic variables and NDVI trends: 1982-1990. Int J Remote Sens 23(18):3873-3878. https://doi. org/10.1080/01431160110119416

Jiao Y, Lei H, Yang D, Huang M, Liu D, Yuan X (2017) Impact of vegetation dynamics on hydrological processes in a semiarid basin by using a land surface-hydrology coupled model. J Hydrol 551:116-131

Kumar A, Kumar M (2020) Estimation of biomass and soil carbon stock in the hydroelectric catchment of india and its implementation to climate change. J Sustain For 39(6):1-16. https://doi. org/10.1080/10549811.2020.1794907

Kumar A, Sharma MP (2017) Effect of vegetation communities and altitudes on the soil organic carbon stock in Kotilbhel-1A catchment, India. CLEAN - Soil, Air Water 45:1-6

Kumar A, Yang T, Sharma MP (2018) Estimation of carbon stock for greenhouse gas emissions from hydropower reservoirs. Stoch Environ Res Risk Assess 32:3183-3193

Kumar A, Yang T, Sharma MP (2019) Greenhouse gas measurement from Chinese freshwater bodies: a review. J Cleane Prod 233:368-378

Li X (1998) Water resources utilization of Tarim River and land desertification effect analysis. J Desert Res 18:46-54

Li B, Tao S (2000) Correlation between AVHRR NDVI and climate factors. Acta Ecologica Sinica 20(5):898-902

Liu H, Zheng L, Yin S (2018) Multi-perspective analysis of vegetation cover changes and driving factors of long time series based on climate and terrain data in Hanjiang River Basin China. Arabi J Geosci 11(17):509. https://doi.org/10.1007/ s12517-018-3756-3

Liu SZ, Zhou L, Qiu CS, Zhang JP, Fang YP, Gao WS (1999) Studies on grassland degradation and desertification of Naqu Prefecture in Tibet autonomous region. Tibet People's Press, Lasha

Maradi N (2015) Ground water suitability for irrigation in the Korama Basin, Southern Zinder Niger. Int J Res 2(8):55-64

Meng M, Huang N, Wu M, Pei J, Wang J, Niu Z (2019) Vegetation change in response to climate factors and human activities on the Mongolian Plateau. Peer J 7:7735-7735

Nemani RR (2003) Climate-driven increases in global terrestrial net primary production from 1982 to 1999 . Science 300(5625):1560 1563. https://doi.org/10.1126/science. 1082750

Ni J, Harrison SP, Colin Prentice I, Kutzbach JE, Sitch S (2006) Impact of climate variability on present and holocene vegetation: a model-based study. Ecol Modell 191:469-486. https://doi. org/10.1016/j.ecolmodel.2005.05.019

Nicholson SE, Davenport ML, Malo AR (1990) A comparison of the vegetation response to rainfall in the Sahel and East Africa, using normalized difference vegetation index from NOAA AVHRR. Clim Change 17(2-3):209-241

Ning T, Liu W, Lin W, Song X (2015) NDVI variation and its responses to climate change on the Northern Loess Plateau of
China from 1998 to 2012. Adv Meteorol 2015:1-10. https://doi. org/10.1155/2015/725427

Olusegun CF, Adeyewa ZD (2013) Spatial and temporal variation of normalized difference vegetation index (NDVI) and rainfall in the North East Arid Zone of Nigeria. Atmos Clim Sci 3(4):421-426

Piao S, Yin G, Tan J, Cheng L, Huang M, Li Y, Liu R, Mao J, Myneni RB, Peng S (2015) Detection and attribution of vegetation greening trend in China over the last 30 years. Global Change Biol 21(4):1601-1609

Purevdorj TS, Tateishi R, Ishiyama T, Honda Y (1998) Relationships between percent vegetation cover and vegetation indices. Int $\mathrm{J}$ Remote Sens 19(18):3519-3535

Rana K, Kumar M, Kumar A (2020) Assessment of annual shoot biomass and carbon storage potential of grewia optiva: an approach to combat climate change in Garhwal Himalaya. Water Air Soil Pollut 231:450. https://doi.org/10.1007/s11270-020-04825-2

Rasmussen MS (1998) Developing simple, operational, consistent NDVI vegetation models by applying environmental and climatic information: part I assessment of net primary production. Int J Remote Sens 19(1):97-117. https://doi.org/10.1080/01431 1698216459

Rouse Jr JW, Haas RH, Schell JA, Deering DW (1974) Paper A 20. In: Third Earth Resources Technology Satellite-1 Symposium: The Proceedings of a Symposium Held by Goddard Space Flight Center at Washington, DC on December 10-14, 1973: Prepared at Goddard Space Flight Center, vol 351. Scientific and Technical Information Office, National Aeronautics and Space Administration, p 309

Sandao I (2010) Contribution to the knowledge of the current state of water resources dubassin of Korama: South of Zinder Region DEA. University of Niamey, Niamey, p 96

Schmidt H, Gitelson A (2000) Temporal and spatial vegetation cover changes in Israeli transition zone: AVHRR-based assessment of rainfall impact. Int J Remote Sens 21(5):997-1010

Schnur MT, Xie H, Wang X (2010) Estimating root zone soil moisture at distant sites using MODIS NDVI and EVI in a semi-arid region of southwestern USA. Ecol Inform 5(5):400-409. https ://doi.org/10.1016/j.ecoinf.2010.05.001

Schultz PA, Halpert MS (1995) Global analysis of the relationships among a vegetation index, precipitation and land surface temperature. Remote Sens 16(15):2755-2777

Stow D, Daeschner S, Hope A, Douglas D, Petersen A, Myneni R, Zhou L, Oechel W (2003) Variability of the seasonally integrated normalized difference vegetation index across the north slope of Alaska in the 1990s. Int J Remote Sens 24(5):1111-1117

Vorosmarty CJ, Douglas EM, Green PA, Revenga C (2005) Geospatial indicators of emerging water stress an application to Africa AMBIO. A J Human Environ 34(3):230-236

Wang M, Fu J, Wu Z, Pang Z (2020) Spatiotemporal variation of NDVI in the vegetation growing season in the source region of the Yellow River China. ISPRS Int J Geo-Inf 9:282. https://doi. org/10.3390/ijgi9040282

Weiss JL, Gutzler DS, Coonrod JEA, Dahm CN (2004) Long-term vegetation monitoring with NDVI in a diverse semi-arid setting, central New Mexico, USA. J Arid Environ 58(2):249-272

Wu T, Sang S, Wang S, Yang Y, Li M (2020) Remote sensing assessment and spatiotemporal variations analysis of ecological carrying capacity in the Aral Sea Basin. Sci Total Environ 735(15):139562. https://doi.org/10.1016/j.scitotenv.2020.13956 2

Wu Y, Liu S, Abdul-Aziz OI (2012) Hydrological effects of the increased $\mathrm{CO}_{2}$ and climate change in the Upper Mississippi River Basin using a modified SWAT. Clim Change 110(3-4):977-1003

Zhang H, Chang J, Zhang L, Wang Y, Li Y, Wang X (2018) NDVI dynamic changes and their relationship with meteorological

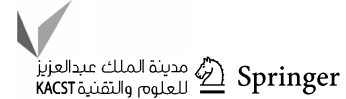


factors and soil moisture. Environ Earth Sci 77(16):582. https:// doi.org/10.1007/s12665-018-7759-x

Zhang S, Li Z, Lin X, Zhang C (2019) Assessment of climate change and associated vegetation cover change on watershed-scale runoff and sediment yield. Water 11(7):1373. https://doi.org/10.3390/ w11071373

Zhang Y, Xu Y, Gu F, Pan X (2003) Correlation analysis of NDVI with climate and hydrological factors in oasis and desert. Acta Phytoecol Sinica 27(6):816-821

Zhao F, Wu Y, Qiu L, Sivakumar B, Zhang F, Sun Y, Sun L, Li Q, Voinov A (2018) Spatiotemporal features of the hydro-biogeochemical cycles in a typical loess gully watershed. Ecol Indic 91:542-554

Zhao F, Wu Y, Qiu L, Sun Y, Sun L, Li Q, Niu J, Wang G (2018) Parameter uncertainty analysis of the SWAT model in a mountain-loess transitional watershed on the Chinese Loess Plateau. Water 10(6):690

Zhi-qiang GAO, Dennis O (2001) The temporal and spatial relationship between NDVI and climatological parameters in Colorado. J Geogr Sci 11(4):411-419

Zipper SC, Motew M, Booth EG, Chen X, Qiu J, Kucharik CJ, Carpenter SR, Loheide SP II (2018) Continuous separation of land use and climate effects on the past and future water balance. $\mathrm{J}$ Hydrol 565:106-122

Publisher's Note Springer Nature remains neutral with regard to jurisdictional claims in published maps and institutional affiliations. 